\title{
333 Pages That Changed Theory of Water Waves
}

\author{
Nikolay Kuznetsov
}

\author{
In memoriam of John $V$. Wehausen
}

The role of John V. Wehausen (he passed away on October 6, 2005) in disseminating the mathematical theory of water waves can hardly be overestimated. His survey article "Surface waves" (Handbuch der Physik, Vol. 9, Springer-Verlag, 1960, pp. 446-778; also coe.berkeley.edu/SurfaceWaves/), written in collaboration with Edmund V. Laitone, has been one of the most influential resources during the fifty-five years that have lapsed since its publication. The late Fritz Ursell had anticipated the importance of this survey: "Wehausen deserves to be congratulated on a scholarly and well-written review....this article...is a most worthy contribution to Encyclopaedia of Physics which many workers in fluid mechanics would be glad to possess" (Math. Rev. 22 (1961), 1776-77).

\section{A Biographical Sketch of J.V. Wehausen}

J. V. Wehausen was born on September 23, 1913, in Duluth, Minnesota, and grew up in a suburb of Chicago. His father, George Wehausen, was an engineer, and his mother, Elizabeth, was a teacher.

It was at the University of Michigan where Wehausen earned his BS and PhD degrees in mathematics in 1934 and 1938, respectively, and an MS degree in physics in 1935 . His PhD advisor was T.H. Hildebrandt, and so Wehausen started to work on transformations in linear topological spaces. In 1937 he began his teaching career as an instructor in mathematics at Brown University, where he met his future wife, Mary Katherine Wertime, a $\mathrm{PhD}$ candidate in mathematics. She

Nikolay Kuznetsov heads the Laboratory for Mathematical Modeling of Wave Phenomena at the Institute for Problems in Mechanical Engineering, Russian Academy of Sciences, St.Petersburg. His email address is n i kolay.g. kuznetsov@ gmai 1 . com.

For permission to reprint this article, please contact: reprint-permission@ams .org.

DOI: http://dx.doi.org/10.1090/noti1285 died in January 2001 after sixty-two years of marriage. From 1938 to 1944 Wehausen held teaching positions at Columbia University and the University of Missouri.

During 1944-46 Wehausen worked in operations analysis for the US Navy, but crucial for him was the subsequent three-year tenure at the David Taylor Model Basin: under the influence of Georg Weinblum - renowned German ship hydrodynamicist - his interest in the theory of water waves and ship hydrodynamics arose. After heading the Mechanics Branch of the Office of Naval Research in 1949-50, Wehausen became executive editor of the Mathematical Reviews and held this position until 1956 (the longest term before the mid-1970s). Recruited by the University of California, Berkeley, he participated in establishing the Department of Naval Architecture in 1958 and stayed there until his retirement in 1984, remaining active in research long after that.

For many years Wehausen edited The Annual Review of Fluid Mechanics together with M. van Dyke and W. G. Vincenti, and he also was a member of the editorial board of the Journal of Engineering Mathematics; its first issue opened with Wehausen's paper.

\section{Nekrasov's Integral Equation}

Under this title a brief section (less than two pages long) appears in "Surface waves". However, this section is best to demonstrate the impact of the article, being devoted to the first account in English of the now renowned Nekrasov's equation. A number of interesting results concerning it were obtained later in Britain. In 1978, G. Keady and J. Norbury showed that the local branch of solutions bifurcating from the trivial solution extends to a global branch for deep water, whereas J. F. Toland demonstrated that there exists a solution which corresponds to a wave of greatest height. Soon after that, C. J. Amick, L. E. Fraenkel, and J. F. 
Toland confirmed the first of three classical Stokes conjectures about steady gravity waves on deep water. Another result of Amick and Toland is a modification of Nekrasov's equation that allowed them to give a full account of a global bifurcation theory for solitary waves on water of finite depth.

Two points were essential for the article's success: Wehausen's good command of the Russian language and his access to Russian books and papers, which became possible after Stalin's death. Of 373 items that he published in Mathematical Reviews, about 10 percent deal with papers in Russian. In theory of water waves and ship hydrodynamics, reviews of the following Soviet researchers dominate along with those of F. Ursell: M. D. Haskind, A. A. Kostyukov, N. N. Moiseev, and L. N. Sretenskii. Wehausen's detailed review of The Exact Theory of Steady Waves on the Surface of a Heavy Fluid by A. I. Nekrasov appeared in 1954, just three years after the booklet had been published by the Soviet Academy of Sciences. Prior to publication of "Surface waves," only J. J. Stoker's Water Waves was published in English. Based mainly on research conducted at the Courant Institute, it can be considered as a detailed presentation of some material only briefly outlined by Wehausen. On the other hand, many books have appeared after 1960, but most of them add not too much to understanding the mathematical aspects of water waves. Analytic Theory of Global Bifurcation by B. Buffoni and J. Toland is an exception: its Part 4 extends essential results on nonlinear waves based on Nekrasov's equation.

\section{THE CHINESE UNIVERSITY OF HONG KONG}

Applications are invited for:-

\section{Department of Mathematics}

Professor / Associate Professor / Assistant Professor (Ref. 1516/024(576)/2)

The Department invites applications from outstanding candidates in the fields of PDE and optimization. Priority will be given to applicants with proven track record in PDE. Applicants with less experience in PDE and optimization will also be considered.

Applicants should have a relevant $\mathrm{PhD}$ degree and an outstanding profile in research and teaching.

Appointment will normally be made on contract basis for up to three years initially commencing August 2016, which, subject to mutual agreement, may lead to longerterm appointment or substantiation later.

Applications will be accepted until the post is filled.

Salary and Fringe Benefits

Salary will be highly competitive, commensurate with qualifications and experience. The University offers a comprehensive fringe benefit package, including medical care, plus a contract-end gratuity for an appointment of two years or longer and housing benefits for eligible appointee. Further information about the University and the general terms of service for appointments is available at https://www2.per. and the general terms or service for appointments is available at htps./Www2.per. to revision by the University.

Application Procedure

Application forms are obtainable (a) at https://www2.per.cuhk.edu.hk/, or (b) in person/by mail with a stamped, self-addressed envelope from the Personnel Office, The Chinese University of Hong Kong, Shatin, Hong Kong.

Please send the completed application form and/or full curriculum vitae, together with copies of qualification documents, a publication list and/or abstracts of selected published papers, and names, addresses and fax numbers/e-mail addresses of three referees to whom the applicants' consent has been given for their providing references (unless otherwise specified), to the Personnel Office by post or by fax to (852) 39420947.

Please quote the reference number and mark 'Application - Confidential' on cover. The Personal Information Collection Statement will be provided upon request. 